\title{
Influence of Annealing on Thermal and Electrical Properties of Carbon Nanotube Yarns
}

\author{
John F. Niven, ${ }^{a}$ Michel B. Johnson, ${ }^{b}$ Stefan M. Juckes, ${ }^{a}$ Mary Anne White ${ }^{a, b, c,}$, , Noe T. \\ Alvarez ${ }^{\mathrm{d}}$, Vesselin Shanov ${ }^{\mathrm{d}}$
}

${ }^{a}$ Department of Physics and Atmospheric Science, Dalhousie University, Halifax, Nova Scotia, B3H 4R2, Canada

${ }^{\mathrm{b}}$ Institute for Research in Materials, Dalhousie University, Halifax, Nova Scotia, B3H 4R2, Canada

${ }^{\mathrm{c}}$ Department of Chemistry, Dalhousie University, Halifax, Nova Scotia, B3H 4R2, Canada

${ }^{\mathrm{d}}$ Department of Environment, Biological, and Medical Engineering, College of Engineering and Applied Science, University of Cincinnati, Cincinnati, OH 45221-0012, USA

\begin{abstract}
The physical properties of dry-spun MWCNT yarns with diameters from 35 to $60 \mu \mathrm{m}$ were systematically determined as a function of annealing up to $2700^{\circ} \mathrm{C}$. Raman spectroscopy showed a $\sim 5$ fold increase in relative CNT crystallinity after annealing. Electrical conductivity and magnetoresistance (in fields up to $9 \mathrm{~T}$ ) were measured from 2 $\mathrm{K}$ to $390 \mathrm{~K}$. Thermal conductivity from $50 \mathrm{~K}$ to $300 \mathrm{~K}$ was determined using the parallel thermal conductance method. The electrical and thermal conductivities of the yarns both increased by over $100 \%$ after annealing to $2700{ }^{\circ} \mathrm{C}$. The influence of adsorbed species on the electrical properties of the yarns was also studied.
\end{abstract}

*Corresponding author: mawhite@dal.ca, 902-494-3894 


\section{Introduction}

Carbon nanotubes (CNTs) exhibit excellent physical properties on the individual nanotube level, including high thermal [1,2] and electrical [3] conductivities and high tensile strength [4]. However, most real world applications require three-dimensional bulk CNT materials, such as arrays [5], sheets [6], and yarns [7]. The physical properties of these materials, such as their mechanical and transport properties are significantly diminished compared to individual CNTs $[8,9,10]$. Several methods have been suggested to improve the properties of bulk CNT materials, such as chemical or metallic doping [11], solvent densification [12], and annealing [13, 14].

High-temperature thermal annealing has been shown to improve the structure of individual CNTs by improving crystallinity, healing defects, and straightening the walls of MWCNTs $[15,16]$. In turn, annealing is expected to improve the thermal and electrical transport properties of CNT materials, as has been observed previously [13, 17]. Annealing provides a reagent-free approach to remove catalyst particles, which could be important for applications where toxicity is a concern [18]. Although thermal annealing of CNT threads has been reported previously by Jin et al., the highest annealing temperatures were only $1700{ }^{\circ} \mathrm{C}$ [13]. These annealing temperatures improve the crystallinity of highly disordered CNTs, but defect healing of higher-quality CNTs seems to require temperatures above $2000{ }^{\circ} \mathrm{C}[14]$. In this work, the thermal and electrical properties of dry-spun CNT yarns were systematically investigated as a function of annealing at temperatures up to $2700{ }^{\circ} \mathrm{C}$. 


\section{Experimental methods}

\subsection{Yarn production}

Multi-walled carbon nanotube (MWCNT) yarns were produced by dry spinning from $340 \mu \mathrm{m}$ tall vertically aligned MWCNT arrays. The MWCNT arrays were grown by chemical vapor deposition (CVD) using ethylene as a precursor gas, as discussed in detail previously $[19,20]$.

CNT yarns were produced using a semi-automated dry-spinning method [21]. Yarns were spun from three CNT arrays (widths $=1 \mathrm{~cm}, 1.5 \mathrm{~cm}$ and $2 \mathrm{~cm}$ ), with resulting yarn diameters ranging between $35 \mu \mathrm{m}$ and $60 \mu \mathrm{m}$. Sections of each yarn were then annealed simultaneously in Ar atmosphere, using three different annealing conditions: non-annealed (pristine), $2300^{\circ} \mathrm{C}$ for 2.5 hours, and $2700^{\circ} \mathrm{C}$ for 2.5 hours.

High-resolution scanning electron microscopy (SEM; Hitachi S-4700) provided information concerning the quality of the yarns. FIG. 1 shows the SEM results for the 55 $\mu \mathrm{m}$ yarn. Each pristine yarn showed a consistent diameter and few surface defects. The annealed yarns appear to show surface damage such as loose bundles, likely caused by handling of the yarns during the annealing process. The yarns produced in this work had diameters between $35 \mu \mathrm{m}$ and $60 \mu \mathrm{m}$, with surface twist angles from $25^{\circ}$ to $35^{\circ}$, increasing with diameter. The deviation in yarn diameter over $\sim 1 \mathrm{~cm}$ lengths was typically on the order of $\pm 3 \mu \mathrm{m}$. 

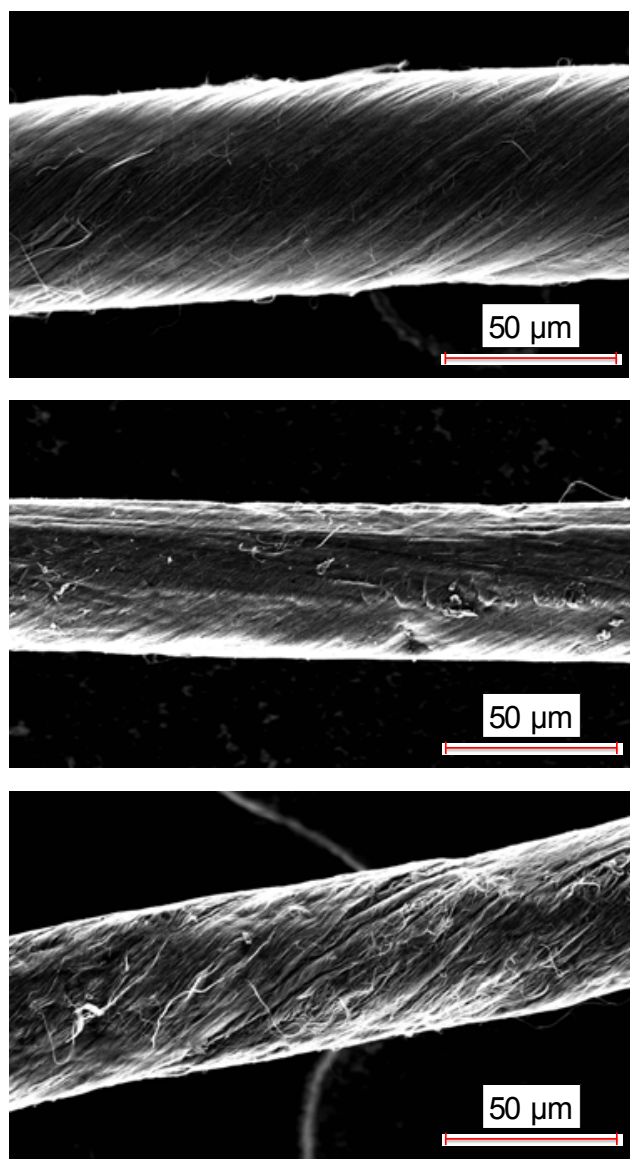

FIG. 1 SEM micrographs of CNT yarns after different annealing conditions: top: pristine; middle: annealed at $2300{ }^{\circ} \mathrm{C}$; bottom: annealed at $2700{ }^{\circ} \mathrm{C}$.

Raman spectroscopy is commonly used to characterize the relative purity and crystallinity of CNT materials [22]. By comparing the intensities of the G-band $\left(1590 \mathrm{~cm}^{-}\right.$ ${ }^{1}$ ) and D-band $\left(1350 \mathrm{~cm}^{-1}\right)$, the relative crystallinities of the various CNT yarns can be compared. Raman spectroscopy was performed using a Renishaw In-Via Raman Microscope with a $514 \mathrm{~nm}$ laser. Small sections of each category of yarn (categorized by 
pristine diameter and thermal treatment) were mounted on glass slides, and Raman spectra were taken at several different locations along the yarn.

FIG. 2 shows the ratio of the G-to-D peak intensities, $I_{G} / I_{D}$, in the Raman spectra for differently annealed $\sim 50 \mu \mathrm{m}$ CNT yarns. (See Supplemental Figure S1 for typical spectra.) It can be seen that $I_{G} / I_{D}$ increases from averages of 1.8 for the pristine yarns, to 4.9 and 7 for the $2300{ }^{\circ} \mathrm{C}$ and $2700{ }^{\circ} \mathrm{C}$ samples, respectively. These results show that high-temperature annealing significantly improved the crystallinity of the yarns, as has been observed previously for both individual CNTs $[15,16]$ and bulk CNT materials [23].

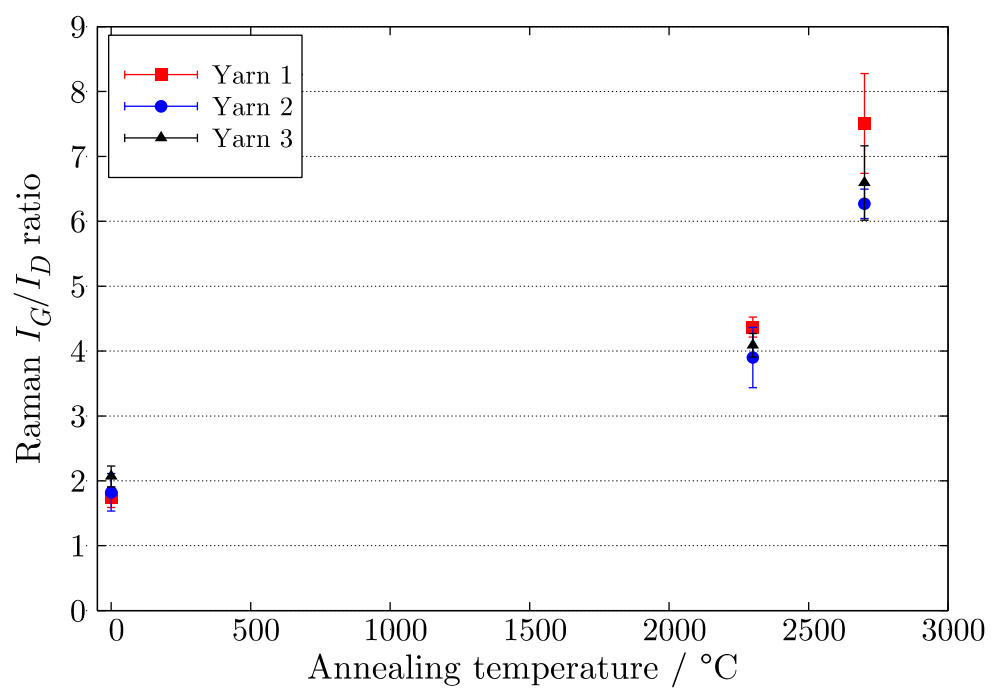

FIG. 2 Raman spectroscopy $I_{G} / I_{D}$ ratios as a function of annealing temperature for three CNT yarns of pristine diameter $\sim 50 \mu \mathrm{m}$ (color online).

The second-order 2D Raman peak also greatly increased in intensity after annealing (Supplemental Figure S1), indicating increased graphitic ordering in the nanotube walls [18]. All peaks become narrower with annealing, consistent with the tubes 
having a more uniform structure and level of graphitization. The wider peaks for the pristine samples suggest that their CNTs have different stages of graphitization.

\subsection{Electrical properties}

The electrical conductivity $(\sigma)$ and magnetoresistance $(\Delta \rho / \rho)$ of the CNT yarns were measured using a Physical Property Measurement System (PPMS; Quantum Design, San Diego, CA). Measurements were made from $390 \mathrm{~K}$ to $2 \mathrm{~K}$ and in magnetic fields, parallel to the yarn axis, up to 9 T. The sample stage, shown in FIG. 3 allows a four-wire resistance measurement, with two 2-cm lengths of yarn mounted simultaneously. The yarns were attached to the four leads using DuPont $4929 \mathrm{~N}$ silver paste to provide good electrical conduction between the leads and yarns. Resistance measurements were made as a function of temperature and magnetic field with a current of $0.1 \mathrm{~mA}$ and a frequency of $93 \mathrm{~Hz}$.

As was demonstrated recently by Lekawa-Rauss et al., adsorbed species can greatly influence the electrical properties of CNT materials [24]. The CNT yarns studied in this work were degassed in vacuum (0.9 Torr) in the PPMS chamber at $T=390 \mathrm{~K}$ (the upper temperature limit of the PPMS). For the pristine yarns, the degassing process caused a small increase $(<2 \%)$ in resistance, $R$, whereas for the annealed yarns $R$ increased by 25 to $50 \%$ (FIG.4). The decrease in the number of defects after annealing likely reduces the strength of the interactions between the CNTs and the adsorbed species, thus making the adsorbed gases easier to remove by degassing, giving a greater change in resistance on degassing for the annealed yarns. 

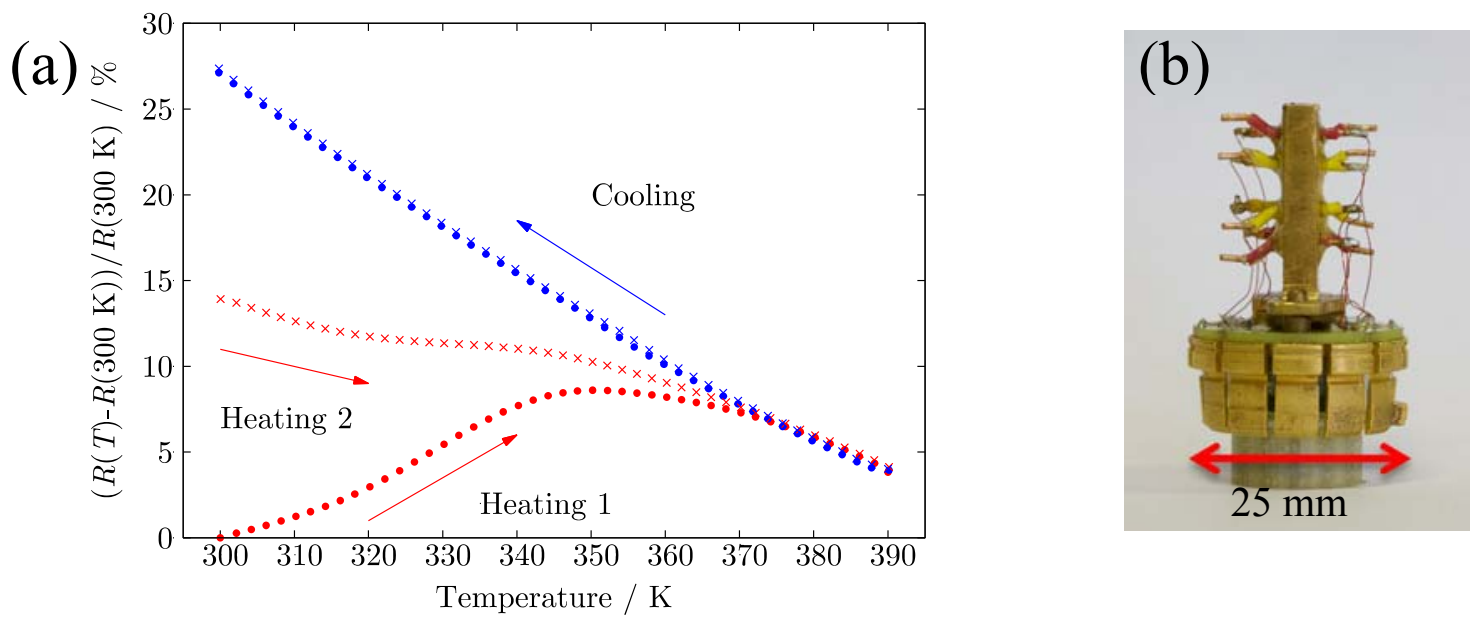

FIG. 3 (a) Difference in resistance relative to $300 \mathrm{~K}$ resistance, showing significant hysteresis in the electrical resistance of an annealed CNT yarn upon degassing at $390 \mathrm{~K}$ and 0.9 Torr for yarn that had been at room conditions for many days (solid circles), compared with the same yarn (crosses) after removing from vacuum to atmosphere for $\mathbf{2 4}$ hours, then returned to vacuum for the measurements. Arrows indicate direction of temperature ramp. Each measurement began at $T=300 \mathrm{~K}$. (b) Photo of sample stage for electrical measurements (color online). 

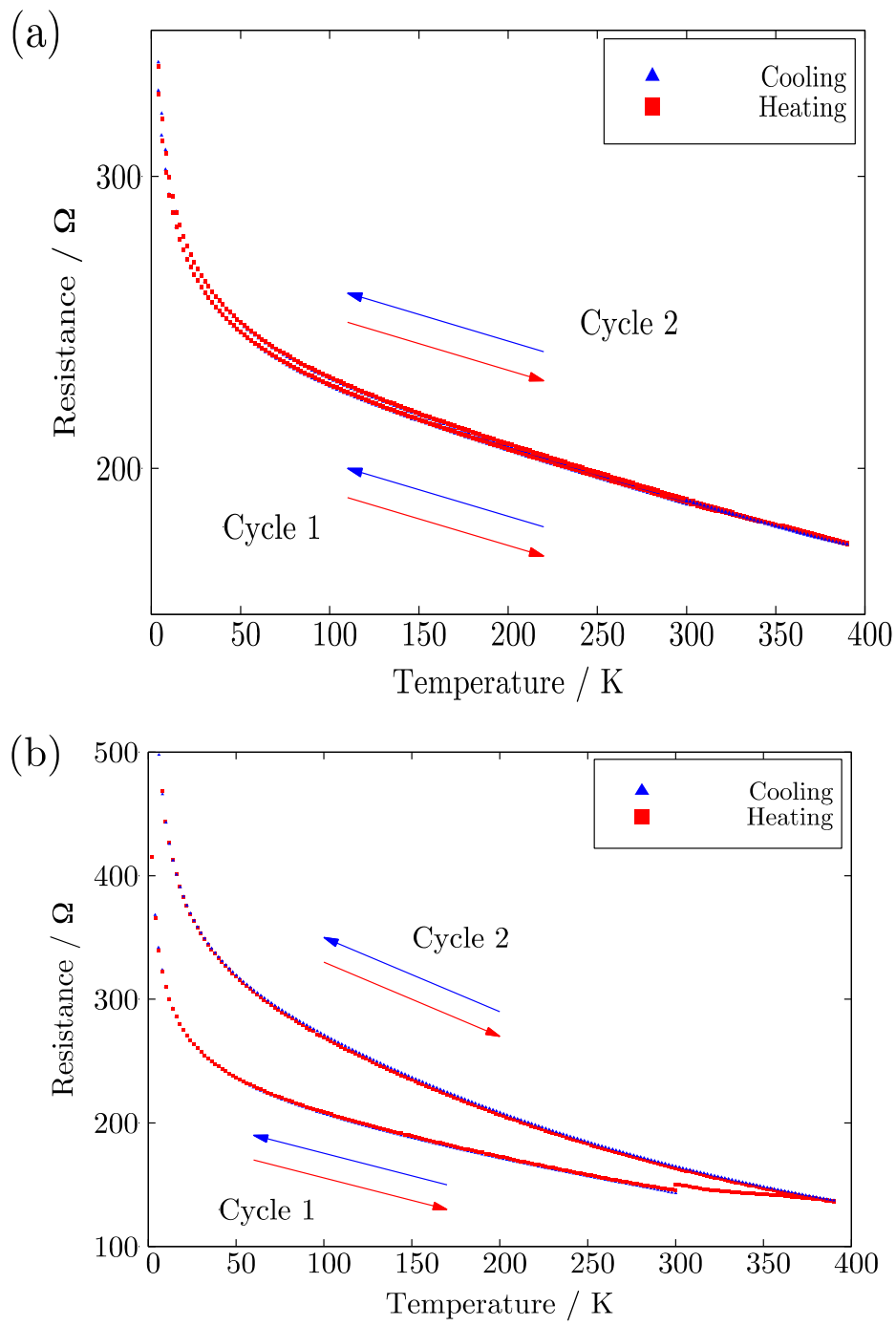

FIG. 4 Electrical resistance as a function of temperature for (a) a $50 \mu \mathrm{m}$ pristine CNT yarn and (b) a $50 \mu \mathrm{m} 2700{ }^{\circ} \mathrm{C}$ annealed CNT yarn. In both cases, cycle 1 was from $T=300 \mathrm{~K}$ to $2 \mathrm{~K}$, then to $T=390 \mathrm{~K}$; cycle 2 followed immediately and was from $T=390 \mathrm{~K}$ to $T=2 \mathrm{~K}$, to $T=390 \mathrm{~K}$. Note the greater hysteresis for the annealed yarn (color online).

FIG. 5 shows the electrical resistances and conductivities of differently annealed $\sim 50 \mu \mathrm{m}$ CNT yarns from $390 \mathrm{~K}$ to $2 \mathrm{~K}$. Results are shown for two pieces of each yarn, demonstrating the consistency of the measurements. The uncertainty in $\sigma$ is on the order 
of $10 \%$, with the largest contribution to uncertainty coming from deviations in the yarn diameter.
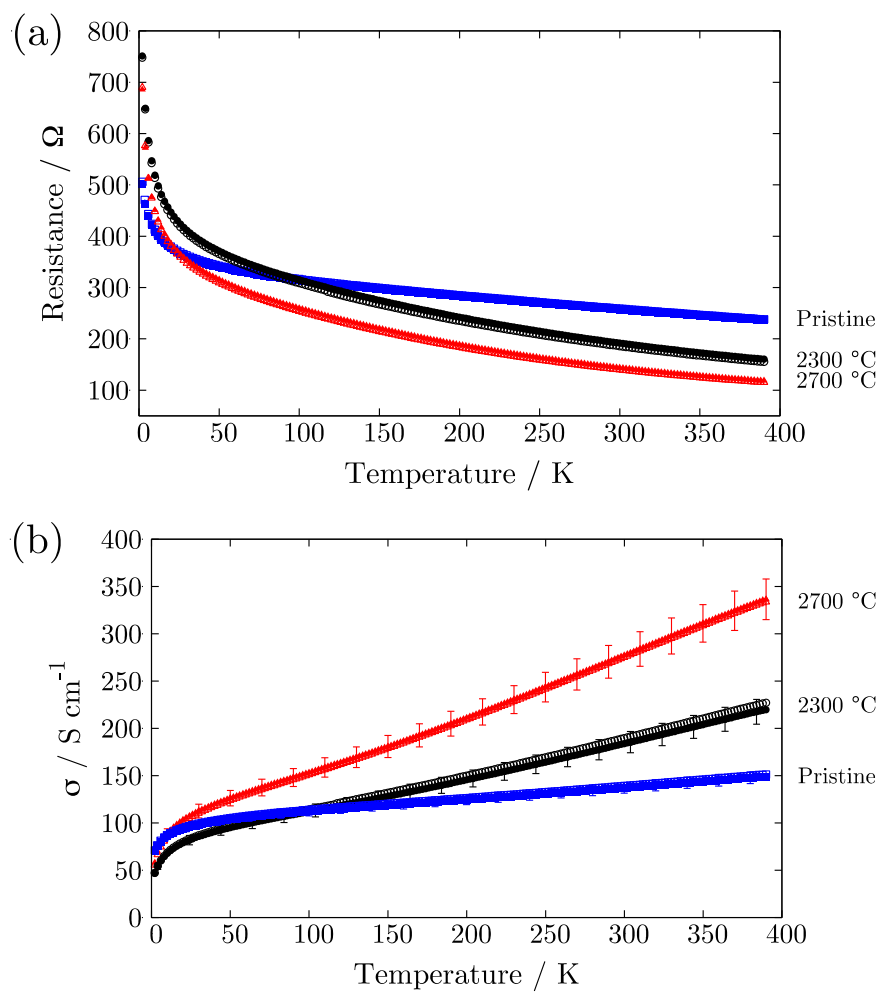

FIG. 5 (a) Electrical resistance and (b) electrical conductivity of three $\sim 50 \mu \mathrm{m}$ CNT yarns with different thermal treatments (color online).

Each yarn showed monotonically increasing resistance with temperature, as is typical for MWCNT materials $[5,6,7]$. Annealing led to an increase in the electrical conductivity at higher temperatures, and also increased the slope, $\mathrm{d} \sigma / \mathrm{d} T$, as has been observed previously $[25,26]$. Below $T=100 \mathrm{~K}$ there is a crossover in conductivity for the annealed and pristine yarn, likely arising from the remaining metal catalyst particles in the pristine samples that are removed by annealing [27]. 
FIG. 6 shows the $T=300 \mathrm{~K}$ electrical conductivities of each category of CNT yarn as a function of yarn diameter and thermal treatment. Annealing at $2300{ }^{\circ} \mathrm{C}$ and $2700{ }^{\circ} \mathrm{C}$ increased $\sigma$ by $\sim 40 \%$ and $\sim 200 \%$, respectively. The general trend of decreased conductivity with increasing yarn diameter has been observed previously [7], and likely is due to increasing yarn porosity with diameter, as has been observed in similar yarns [28].

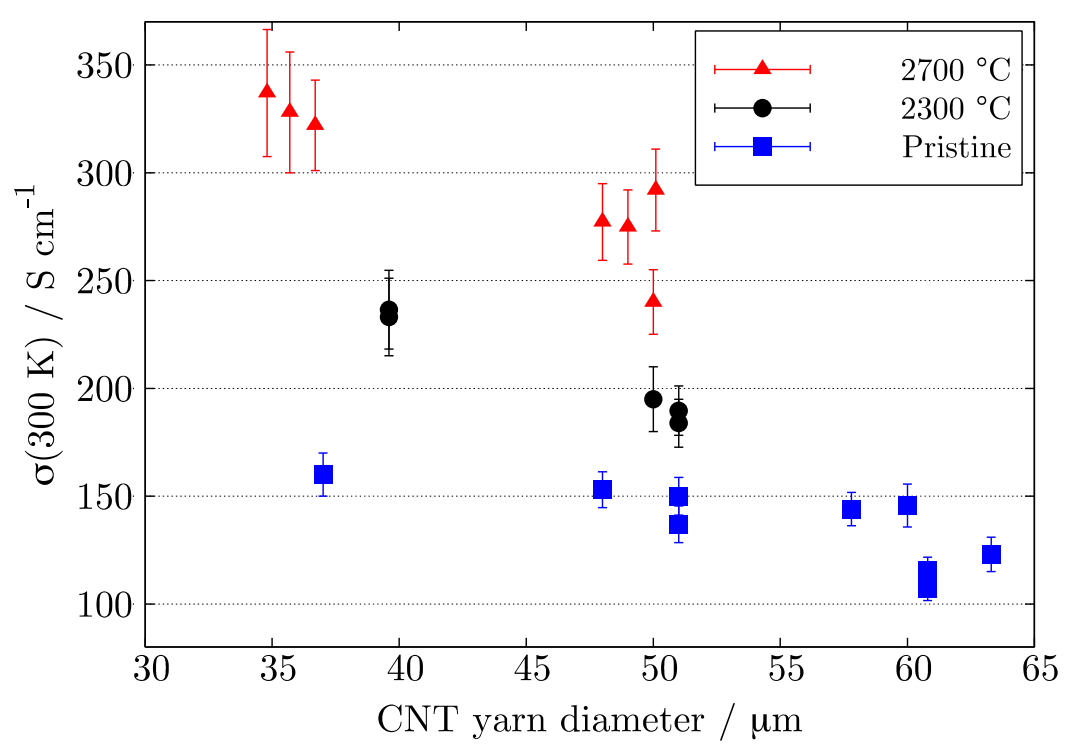

FIG. 6 Electrical conductivities at $T=300 \mathrm{~K}$ for $\mathrm{CNT}$ yarns with different diameters and annealing conditions All samples were degassed at $T=390 \mathrm{~K}$ in vacuum $(0.9$ Torr) prior to measurement (color online).

The high-current limit in atmosphere of the yarns was also measured using a twowire resistance configuration. Current was applied to a $2 \mathrm{~cm}$ length of yarn in $0.5 \mathrm{~mA}$ steps with $4 \mathrm{~s}$ dwell time, and the corresponding voltage was measured up to thermal failure. FIG. 7 shows the current-voltage results for three $\sim 50 \mu \mathrm{m}$ CNT yarns with different thermal treatments. All yarns showed very similar failure, with a bright glow forming between the two leads, followed by the sudden burning of a $\sim 1 \mathrm{~mm}$ section of 
yarn (see Supplemental Figure S2). Annealing increased the maximum current at failure from $60 \mathrm{~mA}$ for the pristine yarn to $80 \mathrm{~mA}$ for the yarn annealed at $2700{ }^{\circ} \mathrm{C}$, likely because the number of defect sites available for oxidation was decreased after annealing.

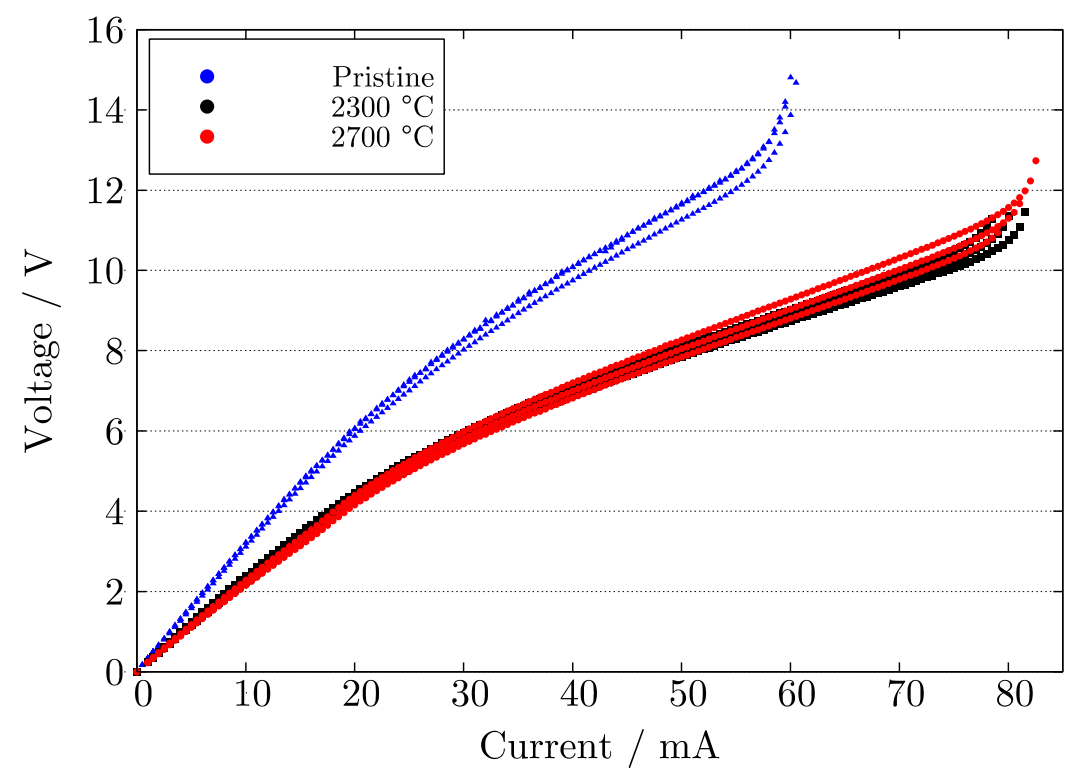

FIG. 7 Current-voltage behavior up to failure in atmosphere for $\sim 50 \mu \mathrm{m}$ CNT yarns, with different thermal treatments. Three segments of yarn with a given thermal treatment (pristine, $2300{ }^{\circ} \mathrm{C}$ anneal, $2700{ }^{\circ} \mathrm{C}$ anneal) were investigated, showing highly reproducible results (color online).

FIG. 8 shows the magnetoresistance as a function of field for $50 \mu \mathrm{m}$ CNT yarns with different thermal treatments. The measurements were made on cooling, after degassing under vacuum at $390 \mathrm{~K}$, and the applied field was parallel to the yarn axis. The magnetoresistance of each yarn was negative from $390 \mathrm{~K}$ to $2 \mathrm{~K}$, with the magnitude increasing as temperature decreased, as is typical for bulk MWCNT materials [6, 7]. The pristine yarns showed $T=2 \mathrm{~K}$ negative magnetoresistance on the order of $15 \%$, similar to the value measured previously for similar CNT yarns [7]. Negative magnetoresistance 
in bulk CNT materials is generally ascribed to a combination of phenomena, mainly weak localization [29] and the formation of Landau levels [30]. Although some models provide a qualitative fit to the magnetoresistance of these CNT yarns [31, 32], they do not provide quantitative insight into the temperature or field dependence.

(a) Pristine

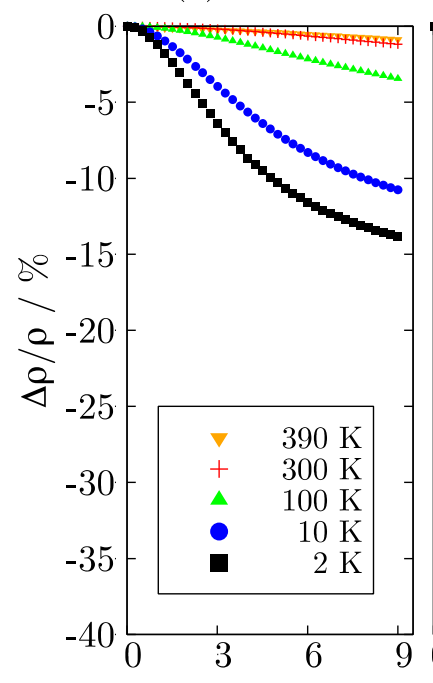

(b) $2300{ }^{\circ} \mathrm{C}$

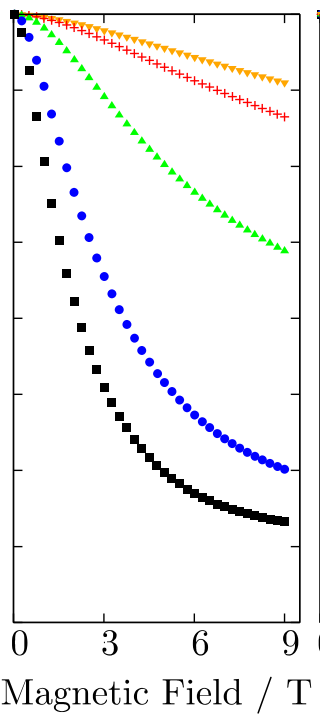

(c) $2700{ }^{\circ} \mathrm{C}$

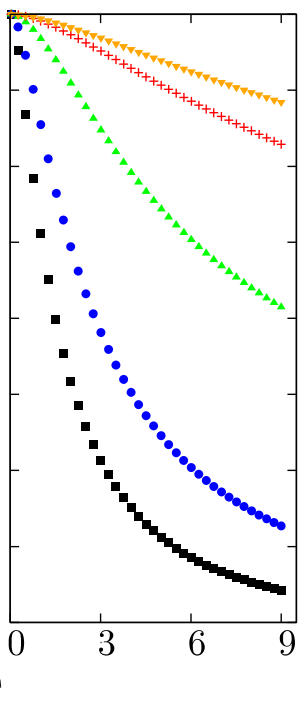

FIG. 8 Magnetoresistance of $50 \mu \mathrm{m}$ CNT yarns that were (a) pristine, (b) annealed at $2300{ }^{\circ} \mathrm{C}$, and (c) annealed at $2700{ }^{\circ} \mathrm{C}$. Measurements were made under vacuum (0.9 Torr) after degassing at $390 \mathrm{~K}$ (color online).

The result of high-temperature annealing was a near doubling of the negative magnetoresistance measured at each temperature, reaching $-37 \%$ at $2 \mathrm{~K}$ for the $2700{ }^{\circ} \mathrm{C}$ annealed yarn. Such an increase in magnitude of magnetoresistance for CNT materials with annealing temperature has been reported previously, approaching the value of highly oriented pyrolytic graphite with increased annealing temperature [33]., but the exact mechanism remains unclear. Explanations for the increased magnetoresistance observed here after high-temperature annealing include improved crystallinity, as measured by Raman spectroscopy (Fig. 2), and/or changes to the electronic structure due to the 
removal of adsorbed species and metallic dopants, as suggested by electrical conductivity measurements (Fig. 4). Further work is needed to delineate the detailed mechanisms concerning the influence of annealing on the magnetoresistance of CNT materials. 


\subsubsection{Thermal conductivity}

Accurate steady-state measurements of the thermal conductivity of unsupported CNT yarns are especially difficult because of the fragile nature of the yarns, so heaters and thermometers cannot be attached directly to the yarn. One technique to measure the thermal conductivity of such samples is the parallel thermal conductance (PTC) method, which is a 1D steady-state measurement with the background conductance accurately measured and subtracted [34]. The PTC method has been used previously to measure the thermal conductivity of CNT sheets [6] and yarns [7].

The PTC measurement platform, shown in FIG. 9 consists of two arms: a "hot" arm containing a strain-gauge heater and connected to the base with cellulose acetate to reduce heat conduction; and a "cold" arm, which is connected to the base with brass to encourage heat conduction. Multiple conductance measurements are necessary to extract the conductance of the sample: the total conductance, $K_{t}$, with the sample attached to both arms; the "radiation" conductance, $K_{\text {rad }}$, with the sample only attached to the hot arm; and the background conductance, $K_{b}$, with the sample completely detached. The sample conductance, $K_{\mathrm{s}}$, is then given by

$$
K_{s}=K_{t}-K_{b}-\frac{1}{2}\left(K_{r a d}-K_{b}\right) .
$$

The PPMS was used as a cryogenic vacuum chamber for PTC measurements. A custom sample stage was built onto a PPMS resistivity puck and is shown in FIG. 9.

The CNT yarns were attached to the two supports using DuPont $4929 \mathrm{~N}$ silver paste to improve heat flow from the CNT yarns to the platform. Between 10 and 15 individual lengths of CNT yarn were mounted at one time in order to increase the contribution of $K_{s .}$. The multiple yarns increased the effective length of sample that is 
measured to $\sim 60-80 \mathrm{~mm}$, and also reduced the influence of yarn defects on the measurement relative to a single section of yarn.

The apparent thermal conductivities, $\kappa_{\text {app }}$, of the CNT yarns were calculated from the measured sample thermal conductance, $K_{s}$, using $\kappa_{\text {app }}=K_{s} L / N A$, where $L$ is the sample length $(\sim 7 \mathrm{~mm}), N$ is the number of samples mounted on the PTC platform $(\sim 15)$ and $A$ is the yarn cross-sectional area. The cross-sectional area was calculated from the outer yarn diameter, determined by SEM. The thermal conductivities are reported as "apparent" values because no attempts were made to correct for the low density of the yarns or of their inhomogeneous (CNT + air) cross sections [35].

FIG. 9 shows the thermal conductivities from $300 \mathrm{~K}$ to $50 \mathrm{~K}$ for $\sim 35 \mu \mathrm{m}$ and $\sim 50$ $\mu \mathrm{m}$ CNT yarns with different thermal treatments. High-temperature annealing clearly increases $\kappa_{\text {app }}$ at each temperature for both yarn diameters.
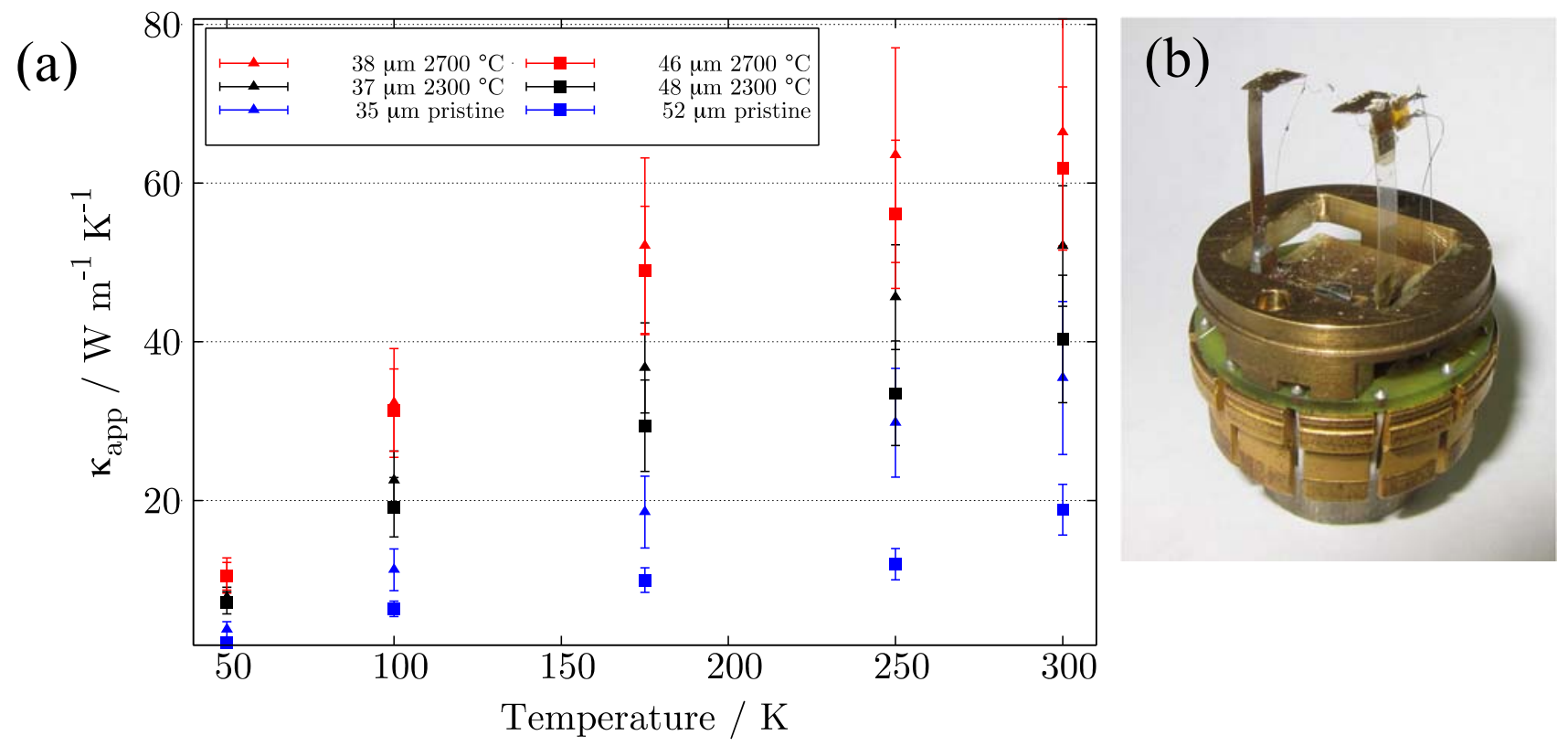

FIG. 9 (a) Thermal conductivities as a function of temperature for $\sim 35 \mu \mathrm{m}$ and $\sim 50$ $\mu \mathrm{m}$ CNT yarns with different thermal treatments. (b) Photograph of the parallel thermal conductance sample platform showing the vertical brass (left) and acetate (right) supports for the yarns. The platform is $\sim 2 \mathrm{~cm}$ in diameter (color online). 
FIG. 10 shows the $T=300 \mathrm{~K}$ thermal conductivities of the yarns with different thermal treatments, as a function of yarn diameter. As with electrical conductivity (FIG. 6 (b)) thermal conductivity decreased with increasing yarn diameter. High-temperature annealing monotonically increased $\kappa_{\text {app }}(300 \mathrm{~K})$ for each yarn diameter by $\sim 200 \%$ for the $2300{ }^{\circ} \mathrm{C}$ samples and between $240 \%$ to $300 \%$ for the $2700{ }^{\circ} \mathrm{C}$ samples.

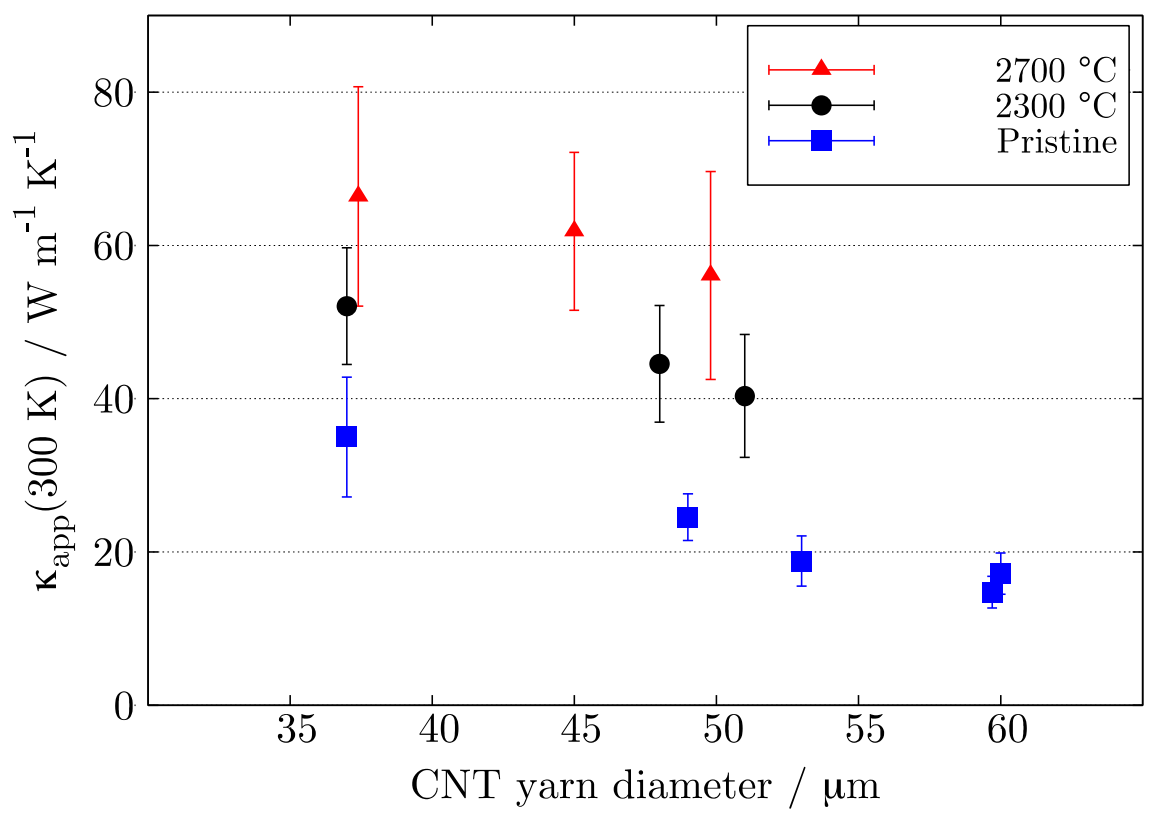

FIG. 10 Apparent thermal conductivities at $T=300 \mathrm{~K}$ for $\mathrm{CNT}$ yarns with different thermal treatments, as a function of yarn diameter (color online).

FIG. 11 shows the values of $\kappa_{\mathrm{app}}(300 \mathrm{~K})$ and $\sigma(300 \mathrm{~K})$ as a function of Raman $I_{G} / I_{D}$ ratio. Both show an approximately linear increase with $I_{G} / I_{D}$. Since conductivity measurements (thermal conductivity in particular) can take a significant amount of time and effort, Raman spectroscopy could be a useful method to quickly assess the relative transport properties of CNT materials. 

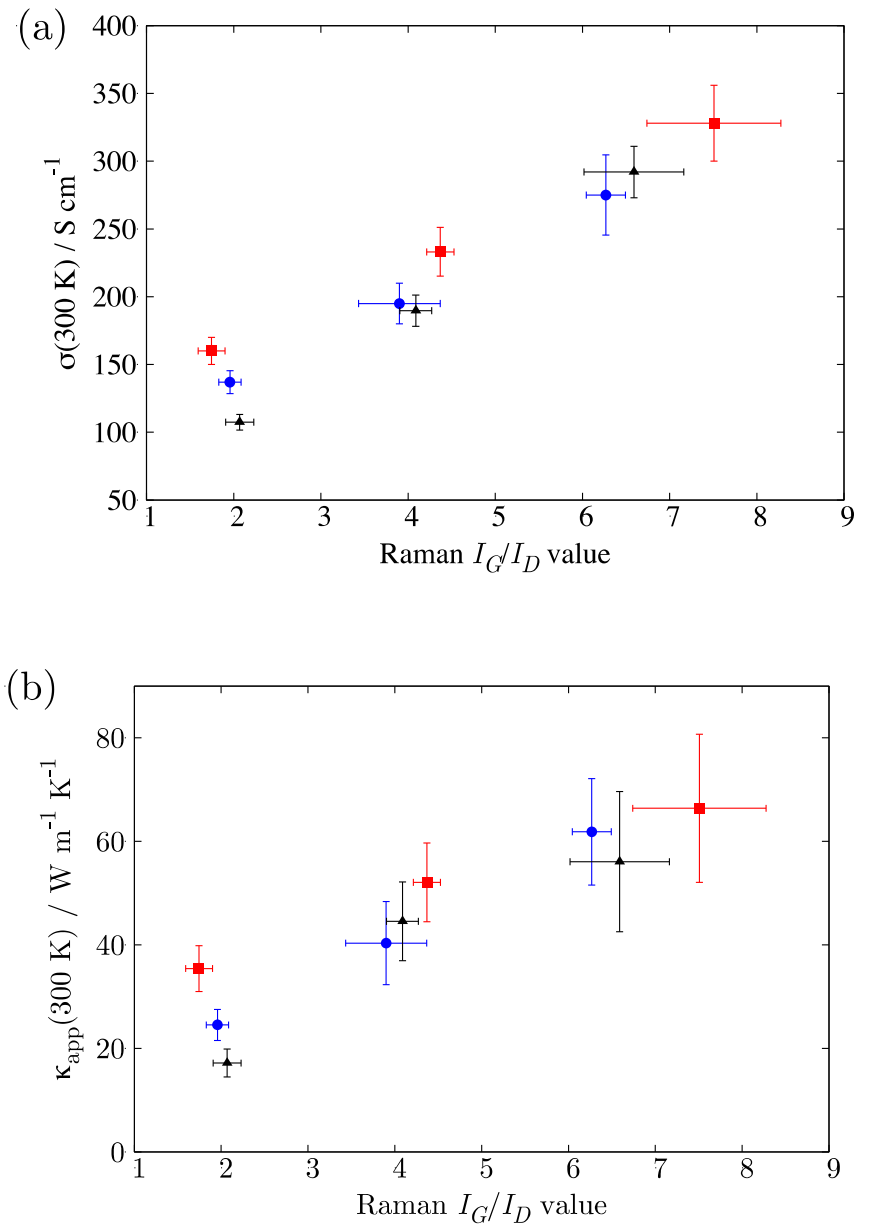

FIG. 11 (a) $T=300 \mathrm{~K}$ electrical conductivities and (b) $T=300 \mathrm{~K}$ thermal conductivities for CNT yarns as a function of $I_{G} / I_{D}$ ratio from Raman spectroscopy. The $\square, \quad$ and $\Delta$ symbols respectively represent results for yarns with pristine diameters of $\sim 38,47$ and $60 \mu \mathrm{m}$ (color online).

\section{Conclusions}

CNT yarns with diameters between $35 \mu \mathrm{m}$ and $60 \mu \mathrm{m}$ were dry-spun from CVDgrown arrays, and annealed at temperatures up to $2700^{\circ} \mathrm{C}$ in Ar. Raman spectroscopy showed an increase in the $I_{G} / I_{D}$ ratio from 1.5 to $\sim 7$ after annealing at $2700{ }^{\circ} \mathrm{C}$, indicating an improvement of the crystallinity of the CNTs in the yarns.

Degassing the CNT yarns at $T=390 \mathrm{~K}$ under vacuum (0.9 Torr) was found to have a large influence on the electrical resistance, especially for the annealed yarns. 
Electrical resistance at $T=300 \mathrm{~K}$ increased by between $20 \%$ to $50 \%$ after degassing for the annealed yarns, but only $<5 \%$ for the pristine yarns. Annealing at $2300{ }^{\circ} \mathrm{C}$ and 2700 ${ }^{\circ} \mathrm{C}$ improved conductivity by $40 \%$ and $200 \%$, respectively. The highest measured value of $\sigma$ was $310 \pm 10 \mathrm{~S} \mathrm{~cm}^{-1}$, for a $37 \mu \mathrm{m}$ yarn that had been annealed at $2700{ }^{\circ} \mathrm{C}$.

Negative magnetoresistance was observed from $T=390 \mathrm{~K}$ to $2 \mathrm{~K}$ for all yarns investigated, and increased in magnitude with increasing field. Magnitude also increased with decreasing temperature. Magnetoresistance was more negative after annealing, as much as $-37 \%$ at $T=2 \mathrm{~K}$ for the $2700{ }^{\circ} \mathrm{C}$ annealed samples.

The thermal conductivity of each CNT yarn was measured using the parallel thermal conductance method. The thermal conductivities of the pristine yarns decreased with diameter, from $30 \pm 8 \mathrm{~W} \mathrm{~m}^{-1} \mathrm{~K}^{-1}$ for a $37 \mu \mathrm{m}$ yarn to $15 \pm 2 \mathrm{~W} \mathrm{~m}^{-1} \mathrm{~K}^{-1}$ for a $60 \mu \mathrm{m}$ yarn (Supplemental Tables S1 to S3). Annealing at $2300^{\circ} \mathrm{C}$ increased $\kappa_{\text {app }}(300 \mathrm{~K})$ by $\sim 200 \%$ and annealing to $2700{ }^{\circ} \mathrm{C}$ increased it by $240 \%$ to $300 \%$.

In summary, high-temperature annealing of dry-spun CNT yarns was found to simultaneously increase both electrical and thermal conductivities, showing that hightemperature annealing is a viable method to improve the transport properties of CNT yarns.

\section{Acknowledgements}

The authors thank J.-H. Pöhls for useful discussions, and P. Scallion and A. George (Dalhousie) for SEM assistance. The work at Dalhousie University was supported by NSERC (grants to M.A.W., postgraduate scholarship to J.F.N., and summer assistantship for S.J.), the Nova Scotia Research and Innovation Graduate Scholarship (J.F.N.), as well 
as CFI and other partners that fund the Facilities for Materials Characterization managed

by the Institute for Research in Materials. The UC researchers acknowledge the National

Science Foundation through the following grants: CMMI-0727250; SNM-1120382;

ERC-0812348; and a DURIP-ONR grant.

\section{References}

[1] Berber S, Kwon YK, Tománek D. Unusually high thermal conductivity of carbon nanotubes. Phys. Rev. Lett. 84, 4613-4616 (2000).

[2] Pop E, Mann D, Wang Q, Goodson K, and Dai H. Thermal Conductance of an

Individual Single-Wall Carbon Nanotube above Room Temperature. Nano Lett. $\underline{6}$, 96100 (2006).

[3] Ebbesen TW, Lezec HJ, Hiura H, Bennett JW, Ghaemi HF, and Thio T. Electrical conductivity of individual carbon nanotubes. Nature 382, 54-56 (1996).

[4] Yu M-F, Lourie O, Dyer MJ, Moloni K, Kelly TF, and Ruoff RS. Strength and

Breaking Mechanism of Multiwalled Carbon Nanotubes Under Tensile Load. Science 287, 637-640 (2000).

[5] Jakubinek MB, White MA, Li G, Jayasinghe C, Cho W, Schulz MJ, Shanov V.

Thermal and electrical conductivity of tall, vertically aligned carbon nanotube arrays. Carbon 48, 3947-3952 (2010).

[6] Pöhls JH, Johnson MB, White MA, Malik R, Ruff B, Jayasinge C, Schulz MJ, Shanov V. Physical properties of carbon nanotube sheets drawn from nanotube arrays. Carbon 50, 4175-4183 (2012).

[7] Jakubinek MB, Johnson MB, White MA, Jayasinghe C, Li G, Cho W, Schulz MJ, Shanov V. Thermal and electrical conductivity of array-spun multi-walled carbon nanotube yarns. Carbon $\underline{50}$, 244-248 (2012).

[8] Aliev AE, Lima MH, Silverman EM, Baughman RH. Thermal conductivity of multiwalled carbon nanotube sheets: radiation losses and quenching of phonon modes. Nanotechnol. 21, 035709:1-11 (2010).

[9] De Volder MFL, Tawfick SH, Baughman RH, and Hart AJ. Carbon Nanotubes:

Present and Future Commercial Applications. Science 339 535-539 (2013).

[10] Marconnet AM, Panzer MA, and Goodson KE. Thermal conduction phenomena in carbon nanotubes and related nanostructured materials. Rev. Mod. Phys. $\underline{85}$ 1295-1326 (2013).

[11] Behabtu N, Young CC, Tsentalovich DE, Kleinerman O, Wang X, Ma AWK, Bengio EA, ter Waarbeek RF, de Jong JJ, Hoogerwerf RE, Fairchild SB, Ferguson JB, Maruyama B, Kono J, Talmon Y, Cohen Y, Otto MJ, and Pasquali M. Strong, Light, Multifunctional Fibers of Carbon Nanotubes with Ultrahigh Conductivity. Science $\underline{339}$ 182-186 (2013).

[12] Zhang X, Li Q, Holesinger TG, Arendt PN, Huang J, Kirven PD, Clapp TG, DePaula RF, Liao X, Zhao Y, Zheng L, Peterson DE, and Zhu Y. Ultrastrong, Stiff, and Lightweight Carbon-Nanotube Fibers. Adv. Mater. 19, 4198-4201 (2007). 
[13] Jin R, Zhou ZX, Mandrus D, Ivanov IN, Eres G, Howe JY, Puretzky AA, and Geohegan DB. The effect of annealing on the electrical and thermal transport properties of macroscopic bundles of long multi-wall carbon nanotubes. Physica B $\underline{388}, 326-330$ (2007).

[14] Huang, J.Y.; Ding, F.; Jiao, K.; Yakobson, B. Self-templated growth of carbonnanotube walls at high temperatures. Small $\underline{3}$, 1735-1739 (2007).

[15] Yamamoto G, Shirasu K, Nozaka Y, Sato Y, Takagi T, and Hashida T. Structureproperty relationships in thermally-annealed multi-walled carbon nanotubes. Carbon $\underline{66}$, 219-226 (2014).

[16] Huang W, Wang Y, Luo G, and Wei F. 99.9\% purity multi-walled carbon nanotubes by vacuum high-temperature annealing. Carbon 41, 2585-2590 (2003).

[17] Mattia D, Rossi MP, Kim BM, Korneva G, Bau HH, and Gogotsi Y. Effect of Graphitization on the Wettability and Electrical Conductivity of CVD-Carbon Nanotubes and Films. J. Phys. Chem. B 110, 9850-9855 (2006).

[18] Behler K, Osswald S, Ye H, Dimkovski S, Gogotsi Y. Effect of thermal treatment on the structure of multi-walled carbon nanotubes. J. Nanopart. Res. $\underline{8}, 615-625$ (2006).

[19] Shanov V, Cho W, Malik R, Haase M, Ruff B, Kienzle M, Ochmann T, Mast D, and Schulz M. CVD growth, characterization and applications of carbon nanostructured materials. Surface and Coatings Technology 230, 77-86(2013).

[20] Alvarez, N.T.; Miller, P.; Haase, M.; Kienzle, N.; Zhang, L.; Schulz, M.; Shanov, V. Carbon nanotube assembly at near-industrial natural-fiber spinning rates. Carbon $\underline{86}$, 350-357 (2015).

[21] Jayasinghe C, Chakrabarti S, Schulz M, and Shanov V. Spinning yarn from long carbon nanotube arrays. J. Mater. Res. 26, 645-651 (2011).

[22] Dresselhaus MS, Jorio A, Souza Filho AG and Saito R. Defect characterization in graphene and carbon nanotubes using Raman spectroscopy. Phil. Trans. R. Soc. A $\underline{368}$, 5355-5377 (2010).

[23] Pierlot AP, Woodhead AL, and Church JS. Thermal annealing effects on multiwalled carbon nanotube yarns probed by Raman spectroscopy. Spectrochim. Acta Part A $117,598-603$ (2014).

[24] Lekawa-Raus A, Kurzepa L, Kozlowski G, Hopkins SC, Wozniak M, Lukawski D, Glowacki BA, and Koziol KK. Influence of atmospheric water vapour on electrical performance of carbon nanotube fibres. Carbon $\underline{87}$, 18-28 (2015).

[25] Hone J, Llaguno M. C., Nemes N. M., Johnson A. T. Electrical and thermal properties of magnetically aligned single wall carbon nanotube films. Appl. Phys.Lett. $\underline{77}$, 666-668 (2000).

[26] Zhou W, Vavro J, Guthy C, Winey K, Fischer J, Ericson L, Ramesh S, Saini R, Davis V, Kittrell C, Pasquali M, Hauge R, and Smalley R. Single wall carbon nanotube fibers extruded from super-acid suspensions: Preferred orientation, electrical, and thermal transport. J. Appl. Phys. 95, 649-655 (2004).

[27] Chen J, Shan J, Tsukada T, Munekane F, Kuno A, Matsuo M, Hayashi T, Kim Y, and Endo M. The structural evolution of thin multi-walled carbon nanotubes during isothermal annealing. Carbon $\underline{45}$, 274-280 (2007). 
[28] Sears K, Skourtis C, Atkinson K, Finn N, and Humphries W. Focused ion beam milling of carbon nanotube yarns to study the relationship between structure and strength. Carbon 48, 4450-4460 (2010).

[29] Bright AA. Negative magnetoresistance of pregraphitic carbons. Phys. Rev. B 20, 5142-5149 (1979).

[30] Kramer B, MacKinnon A. Localization: theory and experiment. Rep. Prog. Phys. 56, 1469-1564 (1993).

[31] Barzola-Quiquia J, Klingner N, Krüger J, Molle A, Esquinazi P, Leonhardt A, and Martínez MT. Quantum oscillations and ferromagnetic hysteresis observed in iron filled multiwall carbon nanotubes. Nanotechnol. 23, 015707:1-7 (2012).

[32] Barzola-Quiquia J, Esquinazi P, Lindel M, Spemann D, Muallem M, and Nessim G. Magnetic order and superconductivity observed in bundles of double-wall carbon nanotube. Carbon $\underline{88}$, 16-25 (2015).

[33] Kuznetsov VL, Elumeeva KV, Ishchenko AV, Beylina NY, Stepashkin

AA,Moseenkov SI, Plyasova LM, Molina IY, Romanenko AI, Anikeeva OB, and

Tkachev EN. Multi-walled carbon nanotubes with ppm level of impurities. Phys. Status

Solidi B 247, 2695-2699 (2010).

[34] Zawilski BM, Littleton RT, Tritt TM. Description of the parallel thermal

conductance technique for the measurement of the thermal conductivity of small diameter samples. Rev. Sci. Instrum. $\underline{72}$, 1770-1774 (2001).

[35] Nanotube Superfibre Materials, Eds: Schulz MJ, Shanov VN, and Yin Z, Elsevier, 2013. 